\title{
Effectiveness study of atropine for progressive myopia in Europeans
}

\begin{abstract}
Purpose Randomized controlled trials have shown the efficacy of atropine for progressive myopia, and this treatment has become the preferred pattern for this condition in Taiwan. This study explores the effectiveness of atropine $0.5 \%$ treatment for progressive high myopia and adherence to therapy in a non-Asian country.

Methods An effectiveness study was performed in Rotterdam, the Netherlands. Overall 77 children (mean age 10.3 years \pm 2.3 ), of European $(n=53)$, Asian $(n=18)$, and African $(n=6)$ descent with progressive myopia were prescribed atropine $0.5 \%$ eye drops daily. Both parents and children filled in a questionnaire regarding adverse events and adherence to therapy. A standardized eye examination including cycloplegic refraction and axial length was performed at baseline and 1, 4, and 12 months after initiation of therapy. Results Mean spherical equivalent at baseline was $-6.6 \mathrm{D}( \pm 3.3)$. The majority $(60 / 77,78 \%)$ of children adhered to atropine treatment for 12 months; 11 of the 17 children who discontinued therapy did so within 1 month after the start of therapy. The most prominent reported adverse events were photophobia (72\%), followed by reading problems $(38 \%)$, and headaches $(22 \%)$. The progression rate of spherical equivalent before treatment $(-1.0 \mathrm{D} /$ year \pm 0.7$)$ diminished substantially during treatment $(-0.1 \mathrm{D} /$ year \pm 0.7$)$ compared to those who ceased therapy $(-0.5 \mathrm{D} /$ year $\pm 0.6 ; P=0.03)$. Conclusions Despite the relatively high occurrence of adverse events, our study shows that atropine can be an effective and sustainable treatment for progressive high myopia in Europeans.
\end{abstract}

${ }^{1}$ Department of Ophthalmology, Erasmus MC, University Medical Center, Rotterdam, The Netherlands

${ }^{2}$ Department of Optometry and Orthoptics, Faculty of Health, University of Applied Sciences, Utrecht, The Netherlands

${ }^{3}$ Department of Epidemiology, Erasmus MC, University Medical Center, Rotterdam, The Netherlands

Correspondence: CCW Klaver, Department of Ophthalmology, Erasmus MC, University Medical Center, Wytemaweg 80, Rotterdam 3015CN, The Netherlands Tel: +31 107040704 . E-mail: c.c.w.klaver@ erasmusmc.nl

Received: 30 June 2015 Accepted in revised form: 10 February 2016 Published online: 22 April 2016
Eye (2016) 30, 998-1004; doi:10.1038/eye.2016.78; published online 22 April 2016

\section{Introduction}

Worldwide, the prevalence of myopia has been rising dramatically, and it is estimated that 2.5
JR Polling ${ }^{1,2}$, RGW Kok ${ }^{1}$, JWL Tideman ${ }^{1,3}$, B Meskat ${ }^{1}$ and CCW Klaver ${ }^{1,3}$ billion people will be affected by myopia by 2020. ${ }^{1}$ South-East Asia is now facing a myopia frequency up to $95.5 \%$ in young academics, ${ }^{2,3}$ but a rising trend has also been observed in recent European studies. ${ }^{4}$ The high rise also includes the prevalence of high myopia $(<-6 \mathrm{D}$; axial length $\geq 26 \mathrm{~mm}$ ), which in particular is associated with severe complications, such as myopic macular degeneration, retinal detachment, and glaucoma. ${ }^{2}$ The absolute risk of severe visual impairment is $30 \%$ in individuals with axial length of $26 \mathrm{~mm}$, and increases up to $95 \%$ in those with an axial length of $30 \mathrm{~mm}$ or more. ${ }^{5,6}$

These dramatic figures create the need for effective counteractions. Current treatment options for progressive myopia can be categorized in conservative and pharmacological interventions. ${ }^{7}$ The effects of the conservative regimens, except for the orthokeratology, are relatively small. ${ }^{8}$ Pharmacological intervention has a much higher efficacy, in particular treatment with topically applied atropine eye drops. ${ }^{9}$

Atropine, a non-selective muscarinic receptor antagonist (M-antagonist), is the most studied pharmacological agent for the intervention of progressive myopia. ${ }^{10}$ In animals, topical atropine showed an inhibitory effect on lens-induced and -deprived myopia. ${ }^{11}$ In humans, the use of atropine to reduce myopic progression was published decades ago, ${ }^{12}$ but it was not until the ATOM study performed their large randomized clinical trial in 400 children of Asian ethnicity that atropine was acknowledged as an effective treatment for myopia progression. ${ }^{10}$ This 2-year study found $75 \%$ reduction of myopic progression with atropine $1 \%$, and did not report serious side effects. A systematic Cochrane review on atropine studies reported that myopia progression can be reduced by $0.80-1.0 \mathrm{D}$ after a year of treatment of atropine 0.5 and $1 \%$, respectively. ${ }^{7}$

Atropine is the preferred practice pattern for progressive myopia in Taiwan. ${ }^{13}$ As early as the year 2000, the Ophthalmological Society of Taiwan advised to use atropine to slow down 
myopia progression. ${ }^{13}$ This treatment is prescribed to nearly $50 \%$ of Taiwanese children with progressive myopia. ${ }^{13}$ Although topical use of atropine is known to cause photophobia and accommodation lag, these adverse events do not appear to hamper its implementation in Taiwanese children. By contrast, the lighter iris color in Europeans is generally considered as a barrier for its use in the Western world. ${ }^{14}$ Moreover, some studies have suggested that atropine is less effective in persons of nonAsian descent. ${ }^{15}$

The aim of this study was to investigate the effect of atropine for progressive myopia under 'real-world' conditions in a non-Asian country. We compared rates of myopia progression in consecutive children before and after therapy, assessed common complaints, evaluated reasons for discontinuation, and developed practice guidelines.

\section{Methods}

\section{Study design, population, and intervention}

The design was an effectiveness study, and was prospective and clinic-based. The setting was Erasmus Medical Center and Sophia Children's Hospital in Rotterdam, the Netherlands, and all consecutive children younger than 18 years of age presenting with progressive myopia were eligible for the study. Inclusion criteria were spherical equivalent $(\mathrm{SE}) \leq-3 \mathrm{D}$ and SE progression rate $\geq 1 \mathrm{D} /$ year under cycloplegic conditions; exclusion criteria were myopia related to retinal dystrophies or collagen syndromes, and developmental disorders. Eligible children and parents received a patient information leaflet followed by oral consultation. After providing written informed parental consent (parents or legal guardians for children $\leq 12$ years; also including children for ages $12+$ years), participants received a prescription of atropine eye drops $0.5 \%$ (FNA Dutch pharmacists). Both eyes were treated by atropine eye drops once daily before bedtime by the parent. The study and protocol adhered to the tenets of the Declaration of Helsinki, and were approved by the Medical Ethics Committee of the Erasmus Medical Centre.

\section{Eye examination}

A standardized ophthalmological examination was performed at baseline, 1 month, 4 months, and 12 months after initiation of atropine treatment. Best corrected visual acuity was performed with a decimal equivalent (minutes) visual acuity chart at $6 \mathrm{~m}$ distance. Binocular reading visual acuity was performed with the LogMARbased Dutch Radner reading chart at 25 or $40 \mathrm{~cm} .{ }^{16}$ Pupil size was measured with Richmond Products Clear Pupilometer (Albuquerque, NM, USA). At baseline, full cycloplegia was obtained 45 min after administration of $1 \%$ cyclopentolate eye drops. At follow up, cycloplegia was already present at examination due to the use of atropine; this was confirmed by the investigators with dynamic retinoscopy, and was therefore considered a measure of compliance. Subsequently, the refractive error was measured with a Topcon auto refractor KR8900 (Topcon, Tokyo, Japan); in younger children with a Nikon Retinomax 2 auto refractor (Nikon, Tokyo, Japan), and in very young or uncooperative children refractive error was determined by an experienced orthoptist (JRP) performing retinoscopy with a Heine beta 200 retinoscope (Heine Optotechnik, Herrsching, Germany) and lenses according to standard protocols. The same devices were used throughout the study period. Spherical equivalent was calculated using the standard formula: ( $\mathrm{SE}=$ sphere $+1 / 2$ cylinder). Axial length was measured with the IOL Master 500 (Carl Zeiss MEDITEC IOL-master, Jena, Germany) at each visit.

\section{Risk factors and adverse events}

At baseline, and after 4 and 12 months after the start of atropine, as well as 1 month after cessation of therapy, parents and children filled in a questionnaire evaluating adverse events. The questionnaires were filled in independent of each other at different locations; children $<8$ years of age received help of the investigator. The questions for the parents concerned risk factors for myopia, adverse events, and adherence to therapy; the questions for the children concerned only the latter two, and were simplified versions of the same questions for parents.

\section{Statistical analysis}

All data were entered into a database as nominal or ordinal variables. Proportions were calculated, and data before and after start of atropine treatment were compared with Fisher's exact test. Biometric measures of the eye were analyzed using Mann-Whitney $U$ non-parametric test. Throughout the study, $P=0.05$ was used as border of significance.

The annual progression rate before treatment was calculated by subtracting the SE at baseline from the SE estimated 1 year before treatment for each participant. We calculated the progression rate during treatment by subtracting the SE at 1 year follow up $(-6.8 \mathrm{D} \pm 3.6)$ from the SE estimated at baseline $(-6.7 \mathrm{D} \pm 3.6)$. The rate was analyzed with Wilcoxon signed ranks test to identify short term differences during the 1 year of treatment.

Risk of adverse events and adherence to therapy were estimated using logistic and linear regression analysis. Multivariate logistic regression analysis was used to determine the risk of discontinuation of therapy 
with age, gender, baseline SE, and ethnicity in the model. All statistical tests were performed by using IBM SPSS Statistics for Windows, Version 21.0. (IBM Corp., Armonk, NY, USA).

\section{Results}

From March 2011 to July 2013, a total of 84 consecutive progressive myopic children visited our clinic and were considered eligible for this study. Of these, 78 (92.9\%) consented to participation and $6(7.1 \%)$ refused. Of those consented, $1(1.3 \%)$ child was lost to follow up during the course of the study. The remaining 77 children completed 12 months of follow up.

Demographics of the study population are summarized in Table 1. Gender was evenly distributed; the mean age was 10.3 ( \pm 3.2 ) years, and two-third of the children had European ancestry. The mean refractive error $1.1( \pm 0.6)$ year before treatment was $-5.6 \mathrm{D}( \pm 3.9)$. At baseline, mean refractive error was $-6.63 \mathrm{D}( \pm 3.31)$, resulting in a mean progression rate of $-1.0(0.7)$. Half (50.6\%) of the children were already highly myopic (SE $>-6 \mathrm{D}$, ranging from $-6.13 \mathrm{D}$ to $-18.63 \mathrm{D})$. Mean pupil diameter before treatment was $4.4 \mathrm{~mm}$ (95\% CI: 3.3-5.5). The majority $(84.7 \%)$ reported at least one myopic parent. Five children had been adopted, and had no information on the refractive error of the biological parents.

Of the 77 children, 60 (78\%) adhered to therapy for the complete follow up of 1 year. Annual progression rates showed an advantage for the children who stayed on therapy $(0.1 \mathrm{D} /$ year $)$ vs the children who discontinued therapy (0.5D/year) (P 0.03) (Table 2). Mean change in SE from baseline to 1 year before and during the year of treatment is presented in Figure 1. The SE difference from baseline to the first month of treatment appeared to improve by $0.19 \mathrm{D}( \pm 0.41)$ compared to baseline, but this temporary inverse progression of myopia was not sustained thereafter. The SE difference from baseline to 6 and 12 months was significantly lower than before therapy and approached almost 0 (0.12 and $-0.05 \mathrm{D}, P<0.01)$.

Age modified the treatment effect significantly $(P=0.01)$ : children younger than 9 years of age had the lowest treatment effect (annual progression rate $-0.49 \mathrm{D}, \mathrm{CI}:-0.90$ to -0.08 ); $9-12$ year olds had more effect (annual progression rate $-0.06 \mathrm{D}, \mathrm{CI}:-0.47$ to +0.35 ), and older children had the highest treatment effect (annual progression rate 0.02D, CI: -0.27 to +0.3 ). Ethnicity $(P=0.58)$ nor gender $(P=0.76)$ significantly influenced annual progression rate during treatment.

More than half $(36 / 60 ; 60 \%)$ of the children who adhered to therapy did not report any skips in therapy administration. None showed more than $0.5 \mathrm{D}$ accommodation on dynamic retinoscopy. The mean pupil diameter was $7.0 \mathrm{~mm}( \pm 0.63)$ during the follow
Table 1 Distribution of demographics and clinical measures of study participants with progressive myopia

\begin{tabular}{|c|c|}
\hline \multicolumn{2}{|l|}{ Characteristics at baseline } \\
\hline Patients, $n$ & 77 \\
\hline \multicolumn{2}{|l|}{ Gender, n (\%) } \\
\hline Male & $39 / 77(50.6 \%)$ \\
\hline Female & $38 / 77(49.4 \%)$ \\
\hline Mean age in years (SD), (range) & $10.34( \pm 3.21)(2.7-16.8)$ \\
\hline Mean SE in D (SD) & $-6.63( \pm 3.31)$ \\
\hline \multicolumn{2}{|l|}{ Mean age in groups, $\mathrm{n}(\%)$} \\
\hline$<9$ years & $26 / 77(33.8 \%)$ \\
\hline $9-11$ years & $48 / 77(32.5 \%)$ \\
\hline $12-16$ years & $22 / 77(33.8 \%)$ \\
\hline \multicolumn{2}{|l|}{ Ethnicity ${ }^{\mathrm{a}}$} \\
\hline European & $53 / 77(68.8 \%)$ \\
\hline Asian & $18 / 77(23.4 \%)$ \\
\hline African & $6 / 77(7.8 \%)$ \\
\hline \multicolumn{2}{|l|}{ Age started reading ${ }^{\mathrm{a}, \mathrm{b}}, \mathrm{n}(\%)$} \\
\hline$<5$ years & $26 / 72(33.8 \%)$ \\
\hline 5 years & $20 / 72(26.0 \%)$ \\
\hline 6 years & $20 / 72(26.0 \%)$ \\
\hline$>7$ years & $4 / 72(5.2 \%)$ \\
\hline \multicolumn{2}{|l|}{ Reading habits ${ }^{\mathrm{a}, \mathrm{c}}, \mathrm{n}(\%)$} \\
\hline Never & $5 / 70(7.1 \%)$ \\
\hline$<5 \mathrm{~h} /$ week & $33 / 70(42.9 \%)$ \\
\hline 5-15 h/week & $23 / 70(29.9 \%)$ \\
\hline$>15 \mathrm{~h} /$ week & $7 / 70(9.1 \%)$ \\
\hline \multicolumn{2}{|l|}{ Outdoor activities ${ }^{\mathrm{a}}, \mathrm{n}(\%)$} \\
\hline$<1 \mathrm{~h} /$ day & $23 / 77(29.9 \%)$ \\
\hline $1-3 \mathrm{~h} /$ day & $45 / 77(58.4 \%)$ \\
\hline$>3 \mathrm{~h} /$ day & $9 / 77(11.7 \%)$ \\
\hline Parental presence of myopia, $\mathrm{n}^{\mathrm{c}}(\%)$ & $57 / 77(74.0 \%)$ \\
\hline
\end{tabular}

up visits. The most frequent reason for skips was forgetfulness. Overall $61.7 \%$ of children who commenced with atropine, 17 stopped treatment, of whom 11 (64.7\%) within the first 4 weeks (Table 3 ). Adverse events were reported as the primary reason $(82.4 \%)$. The frequency of dropouts was higher in those aged 12 years and over (13.0\% in age $<12$ years $v s 44.4 \%$ in $12+$ years; $P<0.01$ ).

The questionnaires addressing treatment response and adverse events showed remarkable similarity between parents and their children, although children reported complaints at slightly higher frequencies. Adverse events occurred often, $63(82.9 \%)$ reported these by both parents and children. Photophobia (72.4\%) and reading problems (37.7\%) were reported most frequently; $22.4 \%$ reported headaches; and systemic flushes occurred only in a 
Table 2 Spherical equivalent and axial length over time in children who prolonged and ceased atropine therapy

\begin{tabular}{|c|c|c|c|}
\hline & Prolonged therapy, $\mathrm{N}=60(77.9 \%)$ & Ceased therapy, $\mathrm{N}=17(22.1 \%)$ & P value \\
\hline $\begin{array}{l}\text { Age (year) at baseline } \\
\text { study, mean }( \pm)\end{array}$ & $10.0(3.2)$ & $11.4(2.8)$ & 0.09 \\
\hline $\begin{array}{l}\text { Spherical equivalent }(S E) \\
12 \text { months before treatment } \\
\text { Start treatment } \\
12 \text { months after start treatment }\end{array}$ & $\begin{array}{l}\text { SE (D) } \\
-5.6(3.9) \\
-6.7(3.6) \\
-6.8(3.6)\end{array}$ & $\begin{array}{l}\text { SE (D) } \\
-5.7(3.1) \\
-6.5(2.8) \\
-7.1(2.6)\end{array}$ & $\begin{array}{l}0.85 \\
0.80 \\
0.55\end{array}$ \\
\hline $\begin{array}{l}\text { Annual myopic progression rate (PR) } \\
\text { Pre-treatment to start treatment (D/year) } \\
12 \text { months after start treatment (D/year) }\end{array}$ & $\begin{array}{l}-1.0(0.7) \\
-0.1(0.7)\end{array}$ & $\begin{array}{l}-0.9(0.5) \\
-0.5(0.6)\end{array}$ & $\begin{array}{l}0.33 \\
\mathbf{0 . 0 3}\end{array}$ \\
\hline $\begin{array}{l}\text { Axial length }(A L) \\
\text { Start treatment }(\mathrm{mm}) \\
12 \text { months after start treatment }(\mathrm{mm})\end{array}$ & $\begin{array}{l}25.19(0.97) \\
25.54(1.35)\end{array}$ & $\begin{array}{l}25.46(1.21) \\
25.83(1.4)\end{array}$ & $\begin{array}{l}0.82 \\
0.66\end{array}$ \\
\hline $\begin{array}{l}\text { Annual AL progression rate }(P R) \\
\text { Pre- treatment to start treatment (mm/year) } \\
12 \text { months after start treatment (mm/year) }\end{array}$ & $\begin{array}{l}\text { n.a. } \\
-0.11(0.20)\end{array}$ & $\begin{array}{c}\text { n.a. } \\
-0.12(0.14)\end{array}$ & 0.73 \\
\hline
\end{tabular}

The bold value represents significant difference $(P \leq 0.05)$ between those who maintained therapy and those who did not.

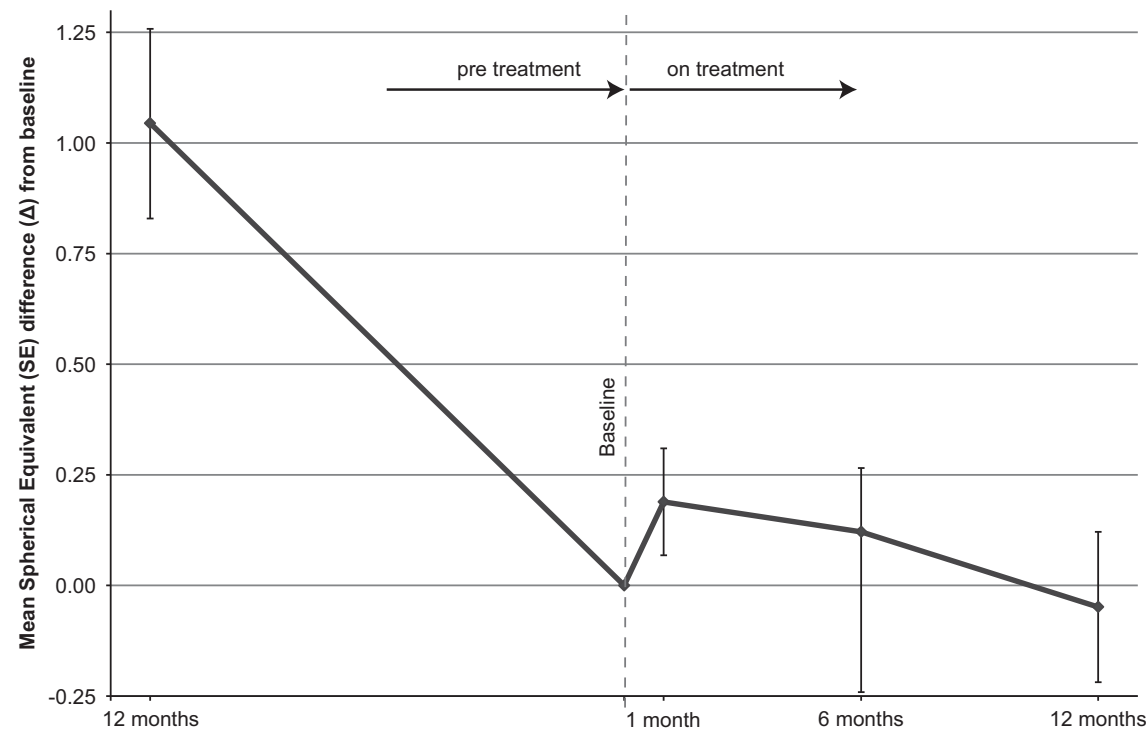

Figure 1 Mean change in SE from baseline 1 year before and during the year of treatment. Error bars present $95 \%$ CI.

minority. Those who discontinued therapy reported reading problems significantly more often than those who maintained therapy $(12 / 15$ (80\%) vs $13 / 54(24.1 \%), P<0.01)$ (Table 4). Other reported events were rare: pain in the eye, irritated eyes, overflow of tears, trouble with depth perception, cosmetically disfiguring pupils, and an unpleasant taste in mouth (all reported only in one patient).

\section{Discussion}

Our study shows that atropine $0.5 \%$ can be an effective treatment for progressive myopia in a European setting. The mean progression rate before the year of intervention was $-1.0 \mathrm{D}( \pm 0.7) /$ year. Atropine $0.5 \%$ reduced this to $-0.1 \mathrm{D}( \pm 0.7) /$ year during treatment. Despite a high frequency of adverse events, most children managed to prolong therapy for the entire study period. Those children who prolonged therapy had a significant advantage over those who stopped $(P=0.03)$. The effect of treatment was dependent on age, and was most prominent in teenagers. Although not powered to test for ethnicity and gender, these did not appear to influence treatment outcome in our study.

We deliberately chose a pragmatic study design to make a translation from findings of efficacy studies to daily practice. Numerous studies including randomized controlled trials have reported on the efficacy of atropine treatment for progressive myopia. An effectiveness study such as ours more closely reflects daily practice as it consisted of a heterogeneous patient population with a large range in refractive errors and age, and inclusion of multiple ethnicities. Other strengths of our study are the 
standardized measurements of cycloplegic refraction, and the cross evaluation of parents and children by questionnaire to improve the validity of data on adherence and adverse events. Among the limitations are the relatively short follow up, and the absence of a flexible dosing regimen which would have allowed tailored therapy for each subject.

Higher concentration atropine eye drops are known for their frequent occurrence of adverse events, and our study confirms this. Most commonly reported adverse events were photophobia and reading problems. Headaches occurred in approximately one-fifth of the patients, but were reported to be mild and transient. Flushes of the cheeks were observed in only three children, but were not a reason to discontinue therapy.

Cessation of therapy most often occurred shortly after the start of therapy. Children who managed to adhere to therapy for 4 weeks were more likely to prolong

Table 3 Adherence to atropine therapy and time and reasons for ceasing

\begin{tabular}{lcc}
\hline & Parent report & Child report \\
\hline Maintained therapy & $60 / 77(77.9 \%)$ & $60 / 77(77.9 \%)$ \\
Adherence & & \\
Full adherence & $39 / 60(65.0 \%)$ & $36 / 60(60 \%)$ \\
Adherence $>6 \times /$ weeks & $17 / 60(28.3 \%)$ & $18 / 60(30 \%)$ \\
Adherence $4-6 \times /$ weeks & $3 / 60(5.0 \%)$ & $5 / 60(8.3 \%)$ \\
Adherence $<4 \times /$ weeks & $1 / 60(1.7 \%)$ & $1 / 60(1.7 \%)$ \\
Reason non-adherence & & \\
$\quad$ Forgotten & $37 / 60(61.7 \%)$ & $28 / 60(46.7 \%)$ \\
Adverse events & $2 / 60(3.3 \%)$ & $3 / 60(5 \%)$ \\
Application eye drops & $1 / 60(1.7 \%)$ & $2 / 60(3.3 \%)$ \\
& & \\
Ceased therapy & $17 / 77(22.1 \%)$ & $17 / 77(22.1 \%)$ \\
Duration of therapy before ceasing & \\
$<1$ weeks & $7 / 17(41.2 \%)$ & $7 / 17(41.2 \%)$ \\
$1-4$ weeks & $4 / 17(23.5 \%)$ & $4 / 17(23.5 \%)$ \\
$>4$ weeks & $6 / 17(35.3 \%)$ & $6 / 17(35.3 \%)$ \\
& & \\
Reason for ceasing & & \\
Adverse events & $14 / 17(82.4 \%)$ & $14 / 17(82.4 \%)$ \\
Application eye drops & $1 / 17(5.9 \%)$ & $1 / 17(5.9 \%)$ \\
Other & $2 / 17(11.8 \%)$ & $2 / 17(11.8 \%)$ \\
\hline
\end{tabular}

therapy thereafter. Most important startup difficulties were adaptation to the bright light and coping with reading problems. Following from this observation, we therefore recommend to prescribe transitional multifocal glasses at the initiation of therapy. We also experienced that comprehensive instruction of the parent and child through information brochures and oral clarification was greatly appreciated, and may improve motivation. After cessation of therapy, a rebound, or catch-up, growth spurt has been described. ${ }^{17}$ Tong et al ${ }^{18}$ found that the positive effect of atropine lasted up to 3 years before being caught up by the rebound effect. Maintaining therapy for a longer period of time and tapering with lower concentrations after achieving stability are suggested to prevent this rebound effect. ${ }^{19}$

Atropine is the standard of care for myopia progression in Taiwan. ${ }^{13}$ The reasons for not prescribing atropine for progressive myopia in western countries is as yet unclear. One reason may be the report of a higher efficacy of treatment in Asians than in Europeans. Although our power to study differences herein was low, our study could not confirm any differences between ethnicities. Another reason may be fear for serious and irreversible complications after prolonged use, but this is not substantiated by literature. Long-term effects of atropine treatment have been investigated in both animal as well as human studies, ${ }^{20,21}$ and photochemical damage to the retina due to enlarged pupil for a longer period of time under daylight conditions has not been reported. ${ }^{22,23}$ Therefore, daily atropine appears to be a safe treatment, even if used for several years. ${ }^{12,24,25}$

A remarkable finding was that the refractive error showed a hyperopic shift after 4 weeks, which disappeared after 4 months. This effect could be caused by the stronger cycloplegic effect of atropine over classical cycloplegic agents used in the clinic, such as cyclogyl. ${ }^{26}$ The reduction in refractive error could also be the result of a temporary thickening of the choroid, a phenomenon observed in animal studies. ${ }^{27}$

How atropine manages to interfere with myopia progression has not been well established, neither is

Table 4 Adverse events in children who maintained and ceased therapy

\begin{tabular}{|c|c|c|c|c|}
\hline & \multicolumn{2}{|c|}{ Maintained therapy, n (\%) } & \multicolumn{2}{|c|}{ 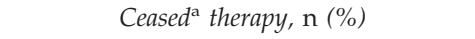 } \\
\hline & Parent report & Child report & Parent report & Child report \\
\hline No & $11 / 60(18.3 \%)$ & $11 / 60(18.3 \%)$ & $2 / 16(12.5 \%)$ & $2 / 16(12.5 \%)$ \\
\hline Photophobia & $36 / 60(60 \%)$ & $42 / 60(70.0 \%)$ & $12 / 16(75.0 \%)$ & $13 / 16(81.2 \%)$ \\
\hline Reading problems ${ }^{\mathrm{b}, \mathrm{c}}$ & $13 / 54(24.1 \%)$ & $14 / 54(25.9 \%)$ & $12 / 15(80.0 \%)$ & $12 / 15(80.0 \%)$ \\
\hline Headache & $4 / 60(6.7 \%)$ & $13 / 60(21.7 \%)$ & $5 / 16(31.2 \%)$ & $4 / 16(25.0 \%)$ \\
\hline Systemic (flushes) & $2 / 60(3.3 \%)$ & $2 / 60(3.3 \%)$ & $1 / 16(6.2 \%)$ & $1 / 16(6.2 \%)$ \\
\hline Other & $6 / 60(10.0 \%)$ & $4 / 60(6.7 \%)$ & $2 / 16(12.5 \%)$ & $3 / 16(18.8 \%)$ \\
\hline
\end{tabular}

${ }^{\mathrm{a}} \mathrm{A}$ total of $16 / 17$ could be included, only 1 participant did not return the questionnaire.

bonly in children who started to read, $n=54$ vs $n=15$.

'Significant difference $(P \leq 0.01)$ between those who maintained therapy and those who did not. 
there agreement on the site of action. ${ }^{28}$ This may be the retina, because amacrine cells can express muscarinic receptors on their cell membrane. ${ }^{29}$ Binding of atropine to the muscarinic receptors of amacrine cells has been hypothesized to increase the release of dopamine, which fits well with the view that dopamine is an inhibitory chemical mediator for eye growth. ${ }^{30}$

Reduction of $y$-aminobutyric acid levels is also a possible mechanism, as this neurotransmitter was shown to be downregulated following atropine treatment in myopiainduced mice. ${ }^{31}$ Other explanations include an effect of atropine via the sclera. Scleral fibroblast cells carry all five muscarinic receptors on their cell membrane and binding to atropine may interfere with scleral remodeling. ${ }^{32}$ The inhibitory effect of atropine is not likely executed through an accommodative mechanism, because the inhibitory effect of atropine on eye growth is also observed in chicks, and these animals activate the ciliary muscle via nicotine receptors rather than the muscarinic receptor. ${ }^{30}$

Taken our findings together with the existing literature, we suggest the following guidelines for doctors treating myopes at risk for high myopia in everyday clinical practice: first, identify and discuss the risk profile of the patient and provide lifestyle advice, such as increase of the time spent outdoors. Second, start intervention with atropine $0.5 \%$ and prescribe transitional multifocal glasses. Third, perform regular follow up examinations including visual acuity, reading acuity, cycloplegic refraction, and axial length. Fourth, adjust treatment regimen. In contrast, when SE and axial length have remained stable for a period of 12 months, gradually taper the atropine concentration to naught.

In conclusion, our study provides external validity of findings from randomized controlled trials and shows that atropine can be effective for progressive myopia in daily clinical practice. Atropine should be considered a treatment option in children at risk of high myopia anywhere in the world.

\section{Summary}

What was known before

- Atropine is known to slow progressive myopia in Asians. It is not widely used in Europe.

\section{What this study adds}

- Atropine eye drops can slow down eye growth in myopic children of European descent, and is tolerated by the majority of children. Intervention with atropine is a treatment option in children with progressive myopia irrespective of ethnicity.

\section{Conflict of interest}

The authors declare no conflict of interest.

\section{References}

1 Morgan IG, Ohno-Matsui K, Saw SM. Myopia. Lancet 2012; 379(9827): 1739-1748.

2 Pan CW, Ramamurthy D, Saw SM. Worldwide prevalence and risk factors for myopia. Ophthalmic Physiol Opt 2012; 32(1): 3-16.

3 Sun J, Zhou J, Zhao P, Lian J, Zhu H, Zhou Y et al. High prevalence of myopia and high myopia in 5060 Chinese university students in Shanghai. Invest Ophthalmol Vis Sci 2012; 53(12): 7504-7509.

4 Williams KM, Bertelsen G, Cumberland P, Wolfram C, Verhoeven VJ, Anastasopoulos E et al. Increasing prevalence of myopia in Europe and the impact of education. Ophthalmology 2015; 122(7): 1489-1497.

5 Vongphanit J, Mitchell P, Wang JJ. Prevalence and progression of myopic retinopathy in an older population. Ophthalmology 2002; 109(4): 704-711.

6 Verhoeven VJ, Wong KT, Buitendijk GH, Hofman A, Vingerling JR, Klaver CC. Visual consequences of refractive errors in the general population. Ophthalmology 2015; 122(1): 101-109.

7 Walline JJ, Lindsley K, Vedula SS, Cotter SA, Mutti DO, Twelker JD. Interventions to slow progression of myopia in children. Cochrane Database Syst Rev 2011; (12): CD004916.

8 Sun Y, Xu F, Zhang T, Liu M, Wang D, Chen Y et al. Orthokeratology to control myopia progression: a metaanalysis. PLoS One 2015; 10(4): e0124535.

9 Gwiazda J. Treatment options for myopia. Optom Vis Sci 2009; 86(6): 624-628.

10 Chua WH, Balakrishnan V, Chan YH, Tong L, Ling Y, Quah BL et al. Atropine for the treatment of childhood myopia. Ophthalmology 2006; 113(12): 2285-2291.

11 Schmid KL, Wildsoet CF. Inhibitory effects of apomorphine and atropine and their combination on myopia in chicks. Optom Vis Sci 2004; 81(2): 137-147.

12 Brodstein RS, Brodstein DE, Olson RJ, Hunt SC, Williams RR. The treatment of myopia with atropine and bifocals. A long-term prospective study. Ophthalmology 1984; 91(11): 1373-1379.

13 Fang YT, Chou YJ, Pu C, Lin PJ, Liu TL, Huang N et al. Prescription of atropine eye drops among children diagnosed with myopia in Taiwan from 2000 to 2007: a nationwide study. Eye (Lond) 2013; 27(3): 418-424.

14 Shih YF, Hsiao CK, Chen CJ, Chang CW, Hung PT, Lin LL. An intervention trial on efficacy of atropine and multi-focal glasses in controlling myopic progression. Acta Ophthalmol Scand 2001; 79(3): 233-236.

15 Li SM, Wu SS, Kang MT, Liu Y, Jia SM, Li SY et al. Atropine slows myopia progression more in Asian than white children by meta-analysis. Optom Vis Sci 2014; 91(3): 342-350.

16 Maaijwee KJ, Meulendijks CF, Radner W, van Meurs JC, Hoyng CB. [The Dutch version of the Radner Reading Chart for assessing vision function]. Ned Tijdschr Geneeskd 2007; 151 (45): 2494-2497.

17 Lin L, Lan W, Liao Y, Zhao F, Chen C, Yang Z. Treatment outcomes of myopic anisometropia with $1 \%$ atropine: a pilot study. Optom Vis Sci 2013; 90(12): 1486-1492.

18 Tong L, Huang XL, Koh AL, Zhang X, Tan DT, Chua WH. Atropine for the treatment of childhood myopia: effect on myopia progression after cessation of atropine. Ophthalmology 2009; 116(3): 572-579.

19 Chia A, Chua WH, Wen L, Fong A, Goon YY, Tan D. Atropine for the treatment of childhood myopia: changes 
after stopping atropine $0.01 \%, 0.1 \%$ and $0.5 \%$. Am J Ophthalmol 2014; 157(2): 451-457 e1.

20 Lawwill T, Crockett S, Currier G. Retinal damage secondary to chronic light exposure, thresholds and mechanisms. Doc Ophthalmol 1977; 44 (2):379-402.

21 Noell WK, Walker VS, Kang BS, Berman S. Retinal damage by light in rats. Invest Ophthalmol 1966; 5(5): 450-473.

$22 \mathrm{Wu}$ J, Seregard S, Algvere PV. Photochemical damage of the retina. Surv Ophthalmol 2006; 51(5): 461-481.

23 Luu CD, Lau AM, Koh AH, Tan D. Multifocal electroretinogram in children on atropine treatment for myopia. Br J Ophthalmol 2005; 89(2): 151-153.

24 Chia A, Chua WH, Cheung YB, Wong WL, Lingham A, Fong A et al. Atropine for the treatment of childhood myopia: safety and efficacy of $0.5 \%, 0.1 \%$, and $0.01 \%$ doses (atropine for the treatment of myopia 2). Ophthalmology 2012; 119(2): 347-354.

25 Kennedy RH, Dyer JA, Kennedy MA, Parulkar S, Kurland LT, Herman DC et al. Reducing the progression of myopia with atropine: a long term cohort study of Olmsted County students. Binocul Vis Strabismus Q 2000; 15(3 Suppl): 281-304.

26 Rosenbaum AL, Bateman JB, Bremer DL, Liu PY. Cycloplegic refraction in esotropic children. Cyclopentolate versus atropine. Ophthalmology 1981; 88(10): 1031-1034.

27 Nickla DL, Zhu X, Wallman J. Effects of muscarinic agents on chick choroids in intact eyes and eyecups: evidence for a muscarinic mechanism in choroidal thinning. Ophthalmic Physiol Opt 2013; 33(3): 245-256.

28 McBrien NA, Stell WK, Carr B. How does atropine exert its antimyopia effects? Ophthalmic Physiol Opt 2013; 33(3): 373-378.
29 Arumugam B, McBrien NA. Muscarinic antagonist control of myopia: evidence for M4 and M1 receptor-based pathways in the inhibition of experimentally-induced axial myopia in the tree shrew. Invest Ophthalmol Vis Sci 2012; 53(9): 5827-5837.

30 McBrien NA, Moghaddam HO, Reeder AP. Atropine reduces experimental myopia and eye enlargement via a nonaccommodative mechanism. Invest Ophthalmol Vis Sci 1993; 34(1): 205-215.

31 Barathi VA, Chaurasia SS, Poidinger M, Koh SK, Tian D, Ho $\mathrm{C}$ et al. Involvement of GABA transporters in atropinetreated myopic retina as revealed by iTRAQ quantitative proteomics. J Proteome Res 2014; 13(11): 4647-4658.

32 Gallego P, Martinez-Garcia C, Perez-Merino P, Ibares-Frias L, Mayo-Iscar A, Merayo-Lloves J. Scleral changes induced by atropine in chicks as an experimental model of myopia. Ophthalmic Physiol Opt 2012; 32(6): 478-484.

(i) (-) $\ominus$ This work is licensed under a Creative Commons Attribution-NonCommercialNoDerivs 4.0 International License. The images or other third party material in this article are included in the article's Creative Commons license, unless indicated otherwise in the credit line; if the material is not included under the Creative Commons license, users will need to obtain permission from the license holder to reproduce the material. To view a copy of this license, visit http://creativecommons.org/licenses/by-nc-nd/4.0/ 